\title{
Machine for preparing phosphors for the fluorimetric determination of uranium
}

By R. E. Stevens, W. H. Wood, K. G. Goetz, and C. A. Horr

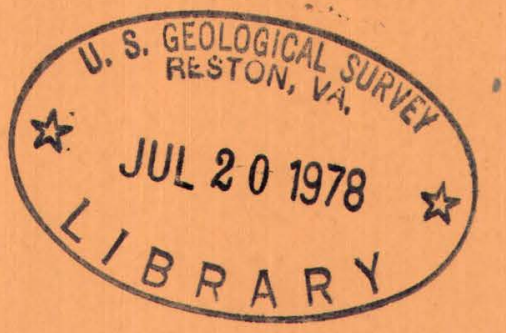

Trace Elements Investigations Report 578

UNITED STATES DEPARTMENT OF THE INTERIOR GEOLOGICAL SURVEY 
Chemistry

This document consists of 22 pages Series A

UNITED STATES DEPARTNENT OF THE INTERIOR

GEOLOGICAL SURVEY

MACHINE FOR PREPARING PHOSPHORS FOR THE FLUORIMETRIC

DETERMINATION OF URANIUN*

By

R. E. Stevens, W. H. Wood, K. G. Goetz, and C. A. Horr

February 1956

Trace Elements Investigations Report 578

This preliminary report is distributed without editorial and technical review for conformity with official standards and nomenclature. It is not for public inspection or quotation.

* This report concerns work done on behalf of the Division of Raw Materials of the U.S. Atomic Energy Commission. 
USGS - TEI- 578

\author{
CHEMISTRY
}

Distribution (Series A)

No. of copies

Argonne National Laboratory ................. I

Atomic Energy Comnission, Washington .. . . . . . . . . . . 2

Division of Raw Materials, Albuquerque . . . . . . . . . . I

Division of Raw Materials, Austin. . . . . . . . . . . . I

Division of Raw Materials, Butte . . . . . . . . . . . . I

Division of Raw Materials, Casper ............... . I

Division of Raw Materials, Denver ............... . 1

Division of Raw Materials, Ishpeming . . . . . . . . . . . 1

Division of Raw Materials, Phoenix ............... . 1

Division of Raw Materials, Rapid City. . . . . . . . . . . . 1

Division of Raw Materials, St。 George ............ . . 1

Division of Raw Materials, Salt Lake City .... . . . . . . . 1

Division of Raw Materials, Washington ............ . . 3

Exploration Division, Grand Junction Operations Office . . . . . I

Grand Junction Operations Office ............... . 1

Technical Information Extension, Oak Ridge . . . . . . . . . 6

Tennessee Valley Authority, Wilson Dam ............ . . 1 U.S.Geological Survey:

Fuels Branch, Washington .................... . 1

Geochemistry and Petrology Branch, Washington . . . . . . . 30

Geophysics Branch, Washington. . . . . . . . . . . . . . I

Mineral Deposits Branch, Washington .............. 1

P. C. Bateman, Menlo Park. . . . . . . . . . . . . . . . 1

A. L. Brokaw, Grand Junction .................. 1

N. M. Denson, Denver .................... . 1

R. L。 Griggs, Albuquerque .................... 1

A. H. Koschmann, Denver ................... . 1

I. R. Page, Washington .................... 1

Q. D. Singewald, Beltsville ................ 1

A. E. Weissenborn, Spokane .................. 1

TEPCO, Denver. ........................ 2

TEPCO, RPS, Washington, (including master) . . . . . . . . 2 
CONTENTS

Page

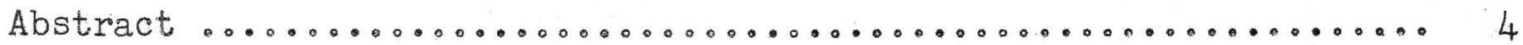

Introduction $\ldots \ldots \ldots \ldots \ldots \ldots \ldots \ldots \ldots \ldots \ldots \ldots \ldots \ldots \ldots \ldots \ldots \ldots \ldots \ldots \ldots$

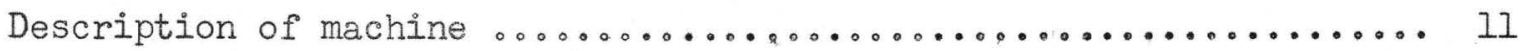

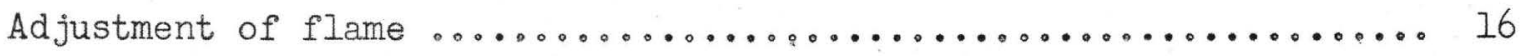

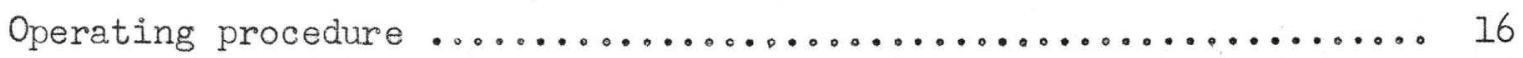

Comparison of precision of hand-fused and machine-fused phosphor ... 17

Advantages gained in time and effort $\ldots \ldots \ldots \ldots \ldots \ldots \ldots \ldots \ldots \ldots$

Adaptation of the machine to other localities ............... 20

Adaptation to dishes of different depth $\ldots . \ldots \ldots \ldots \ldots \ldots \ldots$

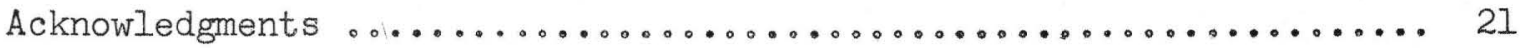

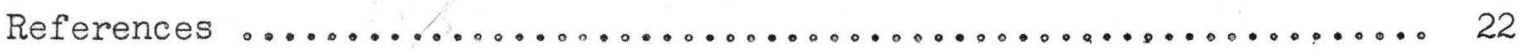

ILIUSTRATIONS

Page

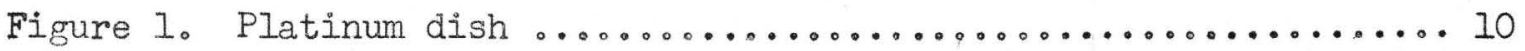

2. Photograph of machine ..................... 12

3. Cutaway drawing of machine, inclined position, showing motor, mounting of dishes, inclining lever, etc.

4. View from above showing opening and mounting positions 14

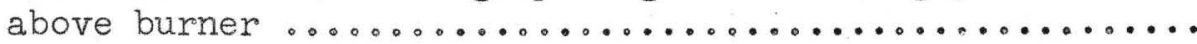

5. Histograms showing precision of hand-fused and

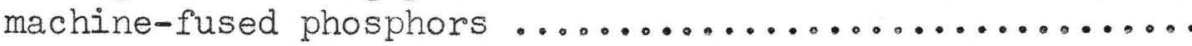


MACHINE FOR PREPARING PHOSPHORS FOR THE FLUORIMETRIC

\section{DETERMINATION OF URANIUM}

By R. E. Stevens, W. H. Wood, K. G。 Goetz, and C.A.Horr

\section{ABSTRACT}

The time saved by use of a machine for preparing many phosphors at one time increases the rate of productivity of the fluorimetric method for determining uranium.

The machine prepares 18 phosphors at a time and eliminates the tedious and time-consuming step of preparing them by hand, while improving the precision of the method in some localities. The machine consists of a ring burner over which the platinum dishes, containing uranium and flux, are rotated. By placing the machine in an inclined position the molten flux comes into contact with all surfaces within the dish as the dishes rotate over the flame. Precision is improved because the heating and cooling conditions are the same for each of the 18 phosphors in one run as well as for successive runs. 


\section{INTRODUCTION}

The frequent determination of uranium in the laboratories of the U.S. Geological Survey and in numerous other laboratories throughout the world makes improvement of the methods for this determination of particular importance at the present time. Part of this analytical effort on uranium is done by volumetric methods, where accurate values for materials high in uranium are sought. However, a large part of the uranium determinations on low-grade material is made by the fluorimetric method because of its high sensitivity and specificity.

The discovery that a trace of uranium in fused sodium fluoride caused an intense yellowagreen fluorescence under ultraviolet light was made by Nichols and Slattery in 1926 (4). Papish and Hoag (5) proposed a bead test for uranium using the fluorescence thus produced, and the test was made quantitative by Hernegger and Karlik (2) in 1935. Since then numerous modifications and improvements have appeared (7), having to do with sequestering of uranium from elements causing quenching of the fluorescence, the composition of the flux used, the method of preparing the fluorescent pads or phosphors containing sodium fluoride and uranium, and instrumentation of the measurement of the fluorescence.

One of the serious handicaps of the fluorimetric method of determining uranium has been in preparing fluorescent pads or phosphors in a reproducible manner without an impractical outlay of time and effort. In the laboratories of the Geological Survey, as well as in many other laboratories, fluorescent pads are prepared by careful hand manipulation of the platinum (or gold) dish, containing uranium and flux, over an open flame, an operation that has been called an art due to the skill required 
and the patience needed to acquire the skill. The molten flux seems to dissolve small but varfable amounts of the platinum (or gold) which cause variations in the quenching of the fluorescence of the phosphors. Much effort has been expended in establishing easily repeatable conditions so that the same quantity of platinum is dissolved from the container in successive preparations. As the preparation of the phosphor is a critical step in the procedure, extended periods are required in training new personnel. After this skill is acquired, the hand preparation of phosphors continues to be a tiring and time-consuming operation.

There has also been difficulty in applying the technique in widely differing localities. An example of variation with differing localities is that in a Washington laboratory of the Geological Survey the establishment of a routine giving reproducible results in the hand preparation of the phosphors has been relatively simple, whereas in a similar laboratory in Denver the establishment of such a repeatable routine has been a continuing problem.

It is interesting to speculate on the causes of discrepancies in standard uranium phosphors prepared by hand in Denver, Colorado, as compared with the excellent reproducibility of such preparations in Washington, D. C. That this is not due to carelessness or lack of skill in the analysts has been show repeatedly by failure of Washington-trained personnel to reproduce the phosphors precisely in Denver, and by Denver personnel successfully doing so with little effort in Washington. The wide differences in humidity and absolute atmospheric pressure, are suggestive. Both cause a change in the rate of cooling of the phosphor, and higher humidity may also provide a mechanism for the release of strain-induced fluorescence. 
A. Go King of the Geological Survey (personal communication) believes that cooling rate is one of several factors affecting fluorescence. Experiments by Stevens showed that filuorescence could be more than doubled by merely reheating the phosphor repeatedly at $150^{\circ} \mathrm{C}$. Differences in the composition of the gas used for heating in the two localities is also suggestive, particularly inasmuch as the gas in Denver comes from two producing areas, either or both of which may be furnishing the gas for a particular day. Differences in the composition of the gases may result in differences in the composition of the spent gases surrounding the melted phosphors. That the composition of the atmosphere surrounding the molten phosphor has an effect is illustrated by the contrasting behavior with regard to the solution of platinum in melting the flux over a flame as compared with melting it in a muffle furnace. The effect of each of these many variables and of other possible ones is difficult to evaluate and to control in successive hand preparation of phosphors.

The statistical study of variables in the hand preparation of the phosphors in Denver, being made by King and others of the Geological Survey, offers the hope of establishing the conditions for more reproducible results in the preparation of the phosphors. It seems apparent that a number of variables, the nature of which can only be surmised, are causing variations in successive preparations by hand.

Machines for performing this step in the procedure have been considered previously. Sadowski and Gentry (8) describe a fusion rack which prepares one phosphor at a time over a flame.

Equipment for preparing a large number of phosphors at one time has been used by Zimmerman (9), Price, Ferretti and Schwartz (6), and by Zim- 
merman, Rabbitts, and Kornelsen (10). Their equipment consists of a single large bumer over which 20 small dishes (7/16-inch internal diameter) containing uranium and flux can be heated at once. There is no adequate provision for stirring the melt. Variations in heat over different parts of the burner and variations in cooling rate from outside to inside positions on the burner are compensated by random arrangement of the unknowns, standards, and blanks. Although the large burner is satisfactory for small dishes, it is not practical for the larger dishes used by many laboratories, because of the size of the burner that would be needed to hold any number of the larger dishes.

Leland Thatcher of the Geological Survey has designed a support for preparing three phosphors at a time in a muffle furnace (unpublished). Adequate swirling of the melts is provided by an externally mounted motor, which swings the support for the dishes in the furnace. Preparation of the phosphors in a muffle furnace is not too satisfactory, however, because of the greater solubility of the platinum in the flux in the oxidizing atmosphere of the furnace, as has been recognized by most users of the fluorimetric method for uranium. When a flame is used, on the other hand, combustion products from the flame prevent to some extent solution of platinum from the dish into the melt.

Recently Michelson (3) discussed the factors involved in preparing phosphors, and described a device for drawing the dish through an electric tube furnace or burner at a repeatable rate. No provision was made for swirling the molten flux.

The machine here described consists essentially of a ring burner, over which a disk with mounts for holding 18 dishes is rotated by means of an 
electric motor. Each dish thus successively and repeatedly comes into contact with each portion of flame from the ring burner. In order that the melt reach all parts of the dish and to provide adequate swirling of the melt the device is put in an inclined position. As a dish rotates around the ring burner with the machine in the inclined position, the melt flows or slowly swirls around the sides of the dish, thus causing solution of uranium from any surface within the dish.

The machine was designed for use in the procedures described by Grimaldi, May, and Fletcher ( 1 ), in which $2 \mathrm{~g}$ of flux ( 45.5 parts by weight of $\mathrm{Na}_{2} \mathrm{CO}_{3}$, 45.5 parts by weight of $\mathrm{K}_{2} \mathrm{CO}_{3}$, and 9 parts by weight of $\mathrm{NaF}$ ) is used for making the phosphor, and with the platinum dishes described by them. Figure 1 , from Geological Survey Circular 199 by the authors just cited, shows a diagram of the dish used. The $4^{-m m}$ flat lip around each dish serves as a means of holding the dish in a horizontal position in the mountings provided in the machine. Similar but much smaller dishes (7/16-inch internal diameter) are used by Price, Ferretti, and Schwartz (6) and by others (9, 10). These also have a flat lip around them and could be mounted in the same way as the dish in figure 1. The machine described here could accommodate a much larger number of these small dishes, or a smaller machine of this design would be adequate for a large number of the small dishes.

Phosphors prepared at one time in the machine show good reproducibility for known quantities of uranium and also separate runs show good agreement. Where precise values are wanted, each run may be standardized by including blanks and phosphors of known uranium content. The machine eliminates the tedious process of hand preparation of phosphors and makes possible a significant increase in the number of samples run per unit of time by the method. Operation of the machine is a simple routine requiring little skill. 


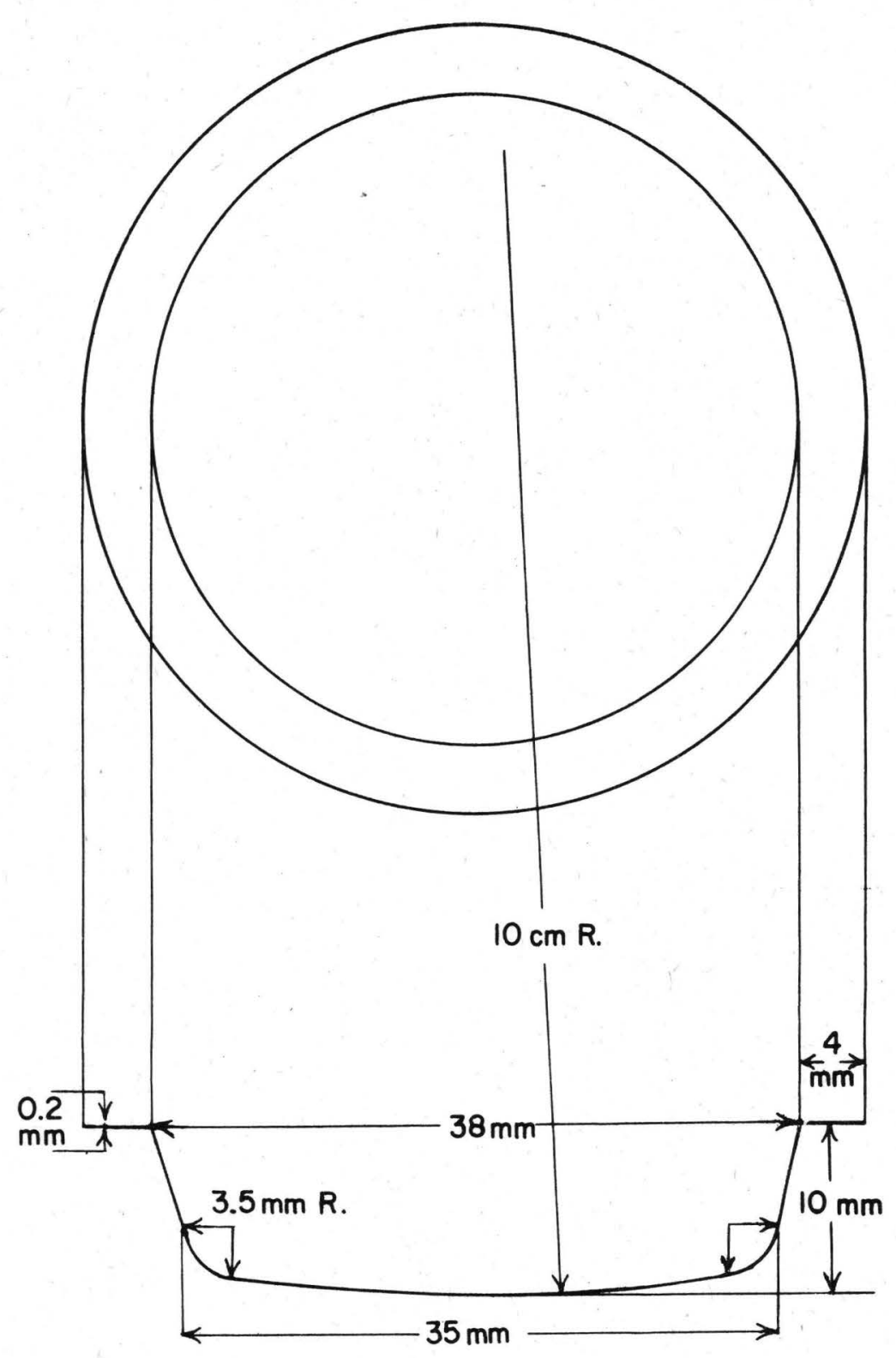

Figure 1. Platirum dish (Grimaldi et al., 1) 
A larger machine than that here described could be built, although problems would be encountered in providing a larger ring burner giving an even and sufficiently hot flame and in preventing the molten flux from swirling over the lips of the dishes, due to their faster rate of travel around a larger circle and the consequently greater centrifugal force. A machine to make 20 fluorescent pads at a time has been built for another laboratory of the Geological Survey and has proved to be satisfactory.

\section{DESCRIPTION OF MACHINE}

The complete machine with the platinum dishes in place is shown in figure 2. The essential feature of the machine is a metal plate which revolves above a ring burner at a fixed height and speed, with fused-silica rods mounted at the edge of the plate to support the platinum dishes. A cutaway drawing of the machine is shown in figure 3.

The upper and lower base plates of the machine are $201 / 2 \times 201 / 20 \times 1 / 4$ inch aluminum, hinged together as shown in figure 3. Ten-inch ventilating holes are cut in the upper and lower base plates, the hole in the upper base plate with an uncut segment, as indicated in figure 3, to leave space for mounting the motor.

The dish-mounting plate is machined from an aluminum casting to $83 / 4$ inch diameter, with a $11 / 4 \times 23 / 4$ inch hub for attachment to an electric motor. This motor is a $1 / 20 \mathrm{hp}, 110 \mathrm{v} \mathrm{a-c} \mathrm{motor.} \mathrm{It} \mathrm{drives} \mathrm{the} \mathrm{dish} \mathrm{mounting}$ plate by means of a gear box which rotates the plate at $10.8 \mathrm{rpm}$. Cable clamps $1 / 8 \times 3 / 16$ inch are fixed to the upper surface of the plate for clamping the fused-silica mountings for the dishes, as shown in figures 2,3 and 4 . 


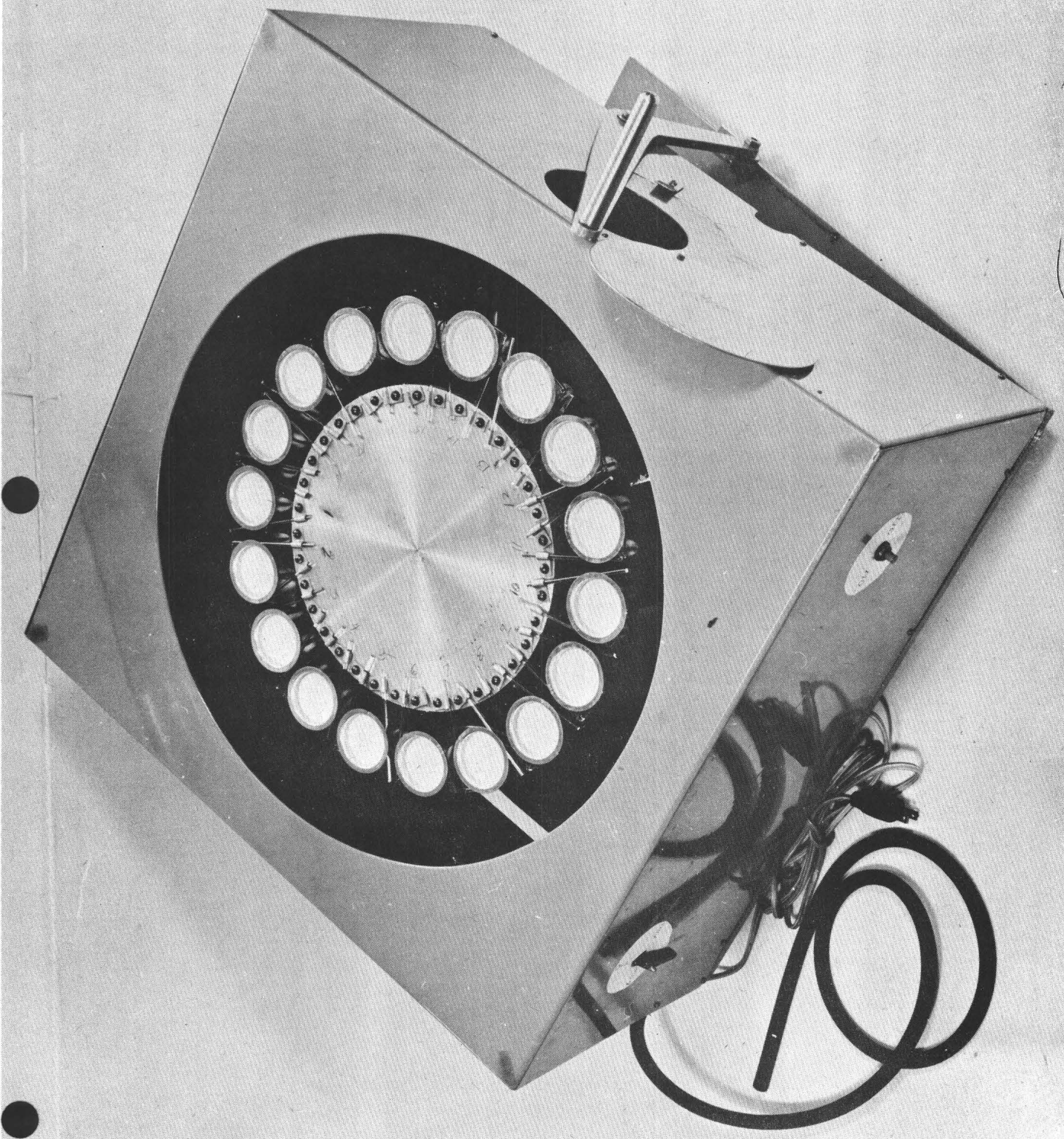

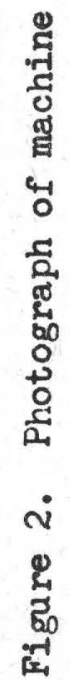




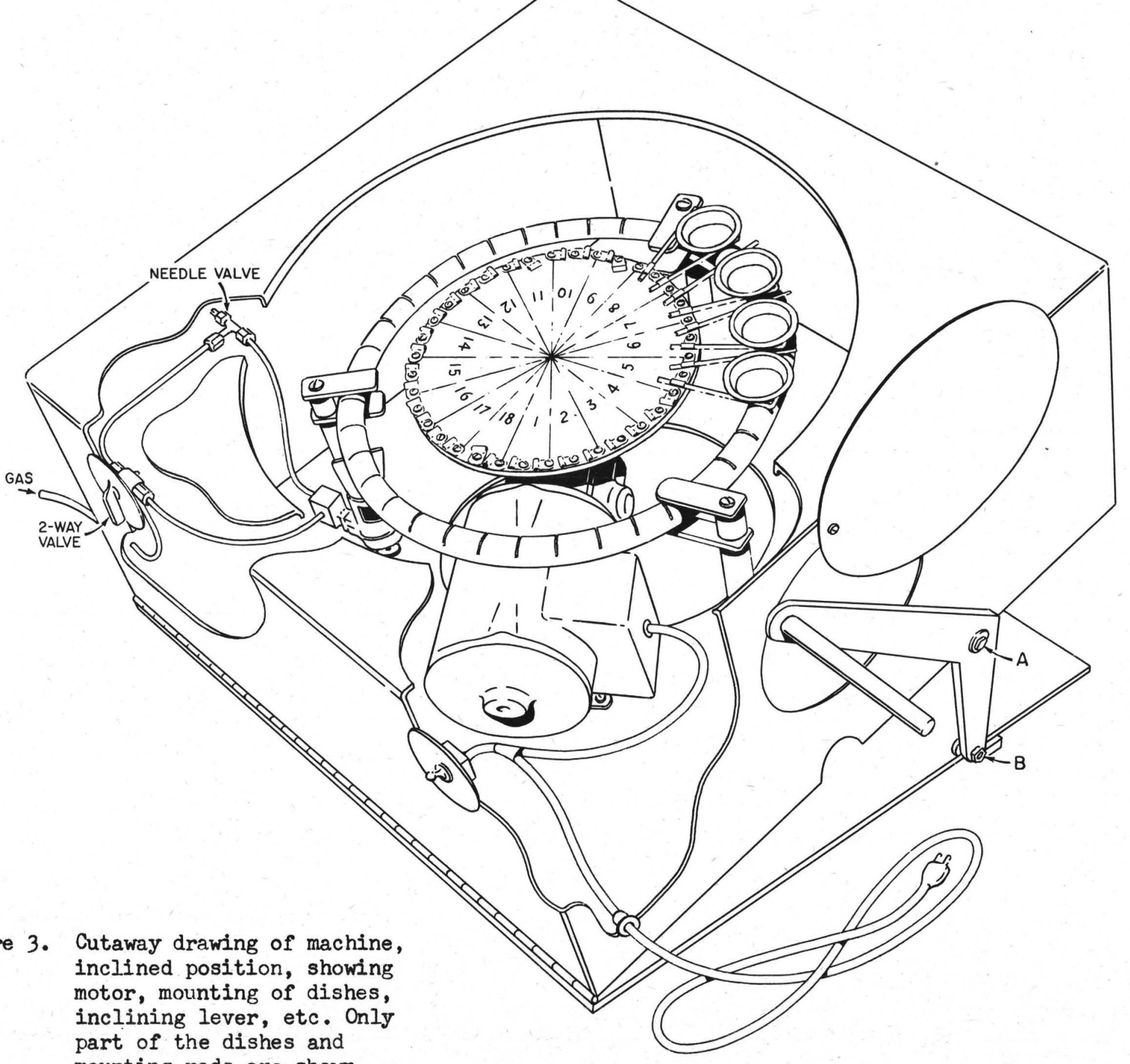




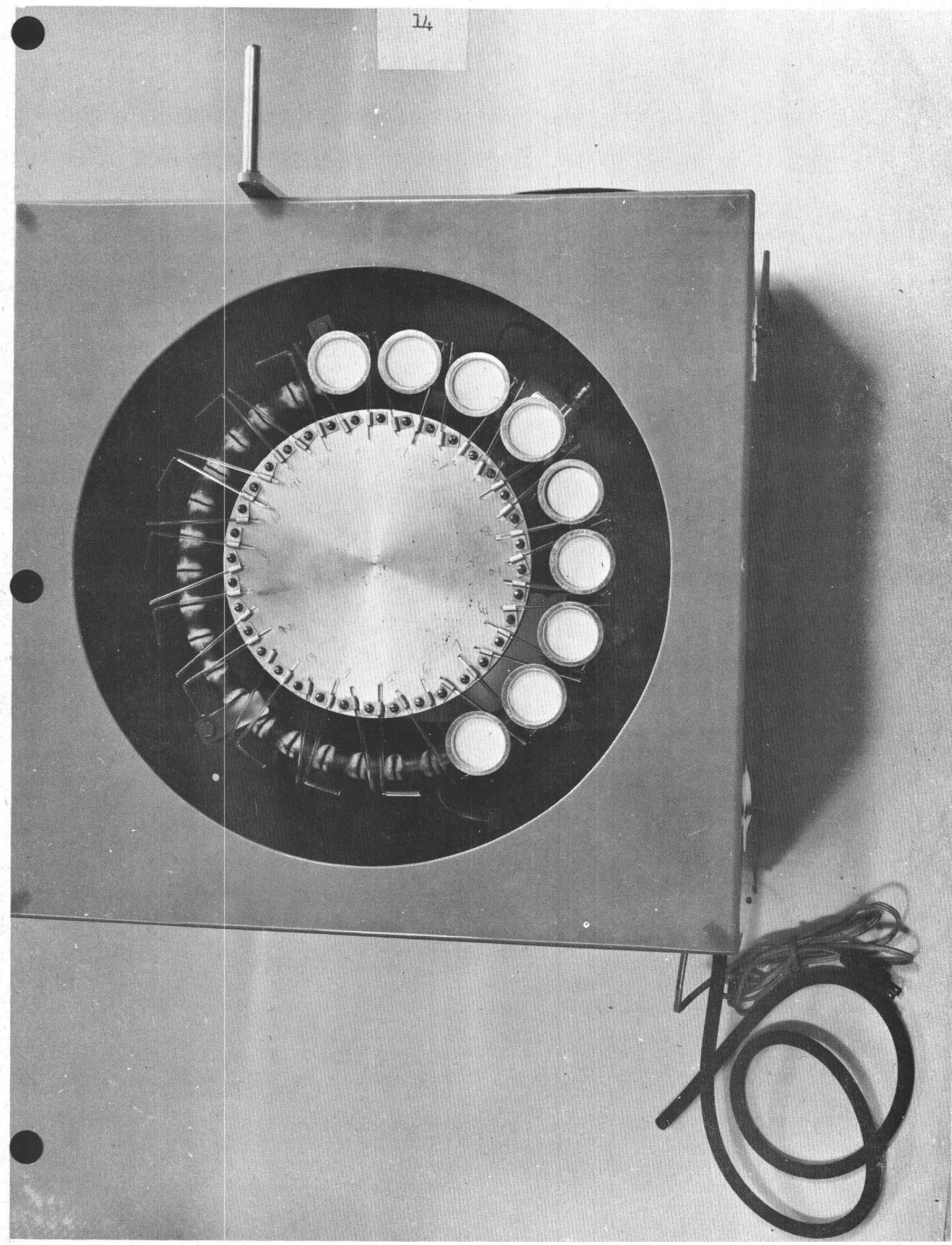

g.

فำ

$\infty$

กี

రิ

(1) द्य

3

응

\%

몽

थ.

\%

$\rightarrow$ 입

$+$

क्ष

I 
The ring burner is formed from standard $1 / 2$ inch water pipe in a circle Il inches in diameter, and the ends welded. Slots, 1/25 inch across, 1/4 inch deep and spaced $I$ inch apart, are cut on the upper surface of the ring. The valve assembly from a Fisher burner is welded to an opening on the bottom of the ring burner. The burner is held $7 / 8$ inch below the dish-mounting plate and centered by adjustable mounts. Two gas inlets are provided, as shown in figure 3, one with unrestricted flow for initial melting of the flux and the other with an adjustable needle valve for heating the flux at or near its melting point. The gas is diverted to the latter inlet by means of the valve handle at the front of the machine.

The two base plates are hinged together at the front of the machine as shown in figure 3. A lever, pivoted at point $\underline{A}$, figure 3, with a roller bearing running to a stop $\underline{B}$, figure 3 , inclines the machine during the fusion period.

The machine is encased in a metal box extending 2 inches above the ring burner, with a $161 / 2$ inch diameter opening in the top.

A cover is provided for the machine to prevent contamination when not in use.

Figure 4 shows the manner of fastening the 3-mm fused-silica mounting rods to the dish-mounting plate. The long arm of one of the I-shaped rods (one arm 3 inches long with a right angle 1 inch arm) is placed under a cable clamp, the rod parallel with the radius of the dish-mounting plate and extending out so that the center of a dish, when mounted, is centered over the ring burner. It is securely fastened with the short arm extending to the right in the same plane as the surface of the plate. A straight 3 inch rod is then clamped similarly to the right of the L-shaped rod in such a position that the bowl of the platinum dish will fit the opening between the rods with a slight 
amount of play. The lips of the dish rest on the fused-silica rods. The remaining pairs of rods are then similarly clamped in position, with equal spacing around the circumference of the dish-mounting plate, as shown in figure 4 , making certain by measurements that all dishes are at equal distances from the dish-mounting plate. In order that each dish fit all positions precisely the dishes should be shaped frequently to exact size with a wooden shaping mold。

\section{ADJUSTMENT OF FLAME}

The high and low flames of the burner are first adjusted to the proper height, and in subsequent use of the machine no further adjustment is normally needed.

With the machine in the horizontal position, 18 dishes, each containing $2 \mathrm{~g}$ of flux (discarded phosphors can be used), are mounted in position in the machine. The motor is turned on. The flame indicator at the front of the box is turned to the high position, the aperture on the right of the box opened, the ring burner lighted, and the aperture closed. After the flux has sintered, the machine is put in the inclined position. The Fisher burner valve under the ring burner is adjusted so that the flux in the dishes melts completely in one to two minutes, The flame indicator is then turned to the low position, and the low adjustment screw, at the left of the box, is adjusted until there is a continuous small cloud of crystals in the molten flux.

\section{OPERATING PROCEDURE}

The following operating procedure for the machine was found satisfactory, although improvements in the procedure may be found on further study。

Place the 18 platinum dishes, containing $2 \mathrm{~g}$ of flux and the uranium to be measured, in the position over the ring burner with the machine in the hori- 
zontal position. Turn the motor on to rotate the dishes around the ring burner. Open the door at the right side of the box, turn the flame indicator to the high position, Iight the burner, and close the side door. Note the time. Continue heating in the horizontal position until the flux is well sintered, then place the machine in the inclined position by pulling the positioning lever at the right of the box until the stop is reached. Continue heating at full heat until most of the flux in the dishes has melted. Turn the flame indicator to the low position. Continue heating with the low flame until five minutes have elapsed from the time the flame was lighted. Turn the flame adjustment to high. Immediately return the machine to the horizontal position with the positioning lever, and turn off the flame. Leave the motor on, continuing the rotation of the dishes over the ring burner during a ten minute cooling period. Turn off the motor. Remove the dishes from the machine, and read the fluorescence of the phosphors with a fluorimeter. Operating at the full heat of the ring burner during the entire operation gave somewhat more erratic results.

\section{COMPARISON OF PRECISION OF HAND-FUSED AND MACHINE-FUSED PHOSPHORS}

The primary purpose in developing a machine for preparing the phosphors was to eliminate the time-consuming and tedious step of preparing them by hand, without the loss of precision in this step of the procedure. Comparisons of hand fusion and machine fusion were made by a number of workers in the laboratory. All results reported showed a definite improvement in repeatability when a machine was used. Most of these comparisons were made with a preliminary model of the machine, I/ identical in principle but

I The preliminary model consisted essentially of a metal ring, with supports for 15 dishes inside the ring, the ring being driven externally by a chain drive to a motor. This model was discontinued in favor of the cheaper construction obtained with direct drive. 
differing in detail from the machine here described. Sufficient work has been done with the present model to show that it duplicates the improvement in results obtained with the first model.

A comparison of results obtained after hand preparation and machine preparation of phosphors (using the model here described) is shown by the histograms of figure 5. These represent runs made in sequence, each of 18 phosphors ( 3 blanks in each run are not shown), to illustrate repeatability of each method of preparation for 0.05 microgram of uranium. The machine-prepared phosphors showed better precision than those prepared by hand, and the two runs with the machine are essentially in agreement. The first run by hand preparation (marked Horr I), although nct representative of normal precision, shows the poor repeatability rarely obtained by hand preparation. The second run by hand preparation seems to more nearly represent an average run in the Denver laboratory.

The machine for preparing the phosphors brings this step in the procedure into more precise control in the Denver area. Still better precision can be expected from future improvements in the machine and in the manner of operating it.

\section{ADVANTAGES GAINED IN TIME AND EFFORT}

The machine also accomplishes another purpose for which it was designed-that of saving time and effort. Considerable time is usually spent in training new personnel in the art of preparing phosphors by hand and trained personnel cannot do this step without an occasional bad result. The phosphors normally take three to five minutes for each preparation by hand, and this task is so tedious that the operator is normally limited to not more than 50 such prepa- 

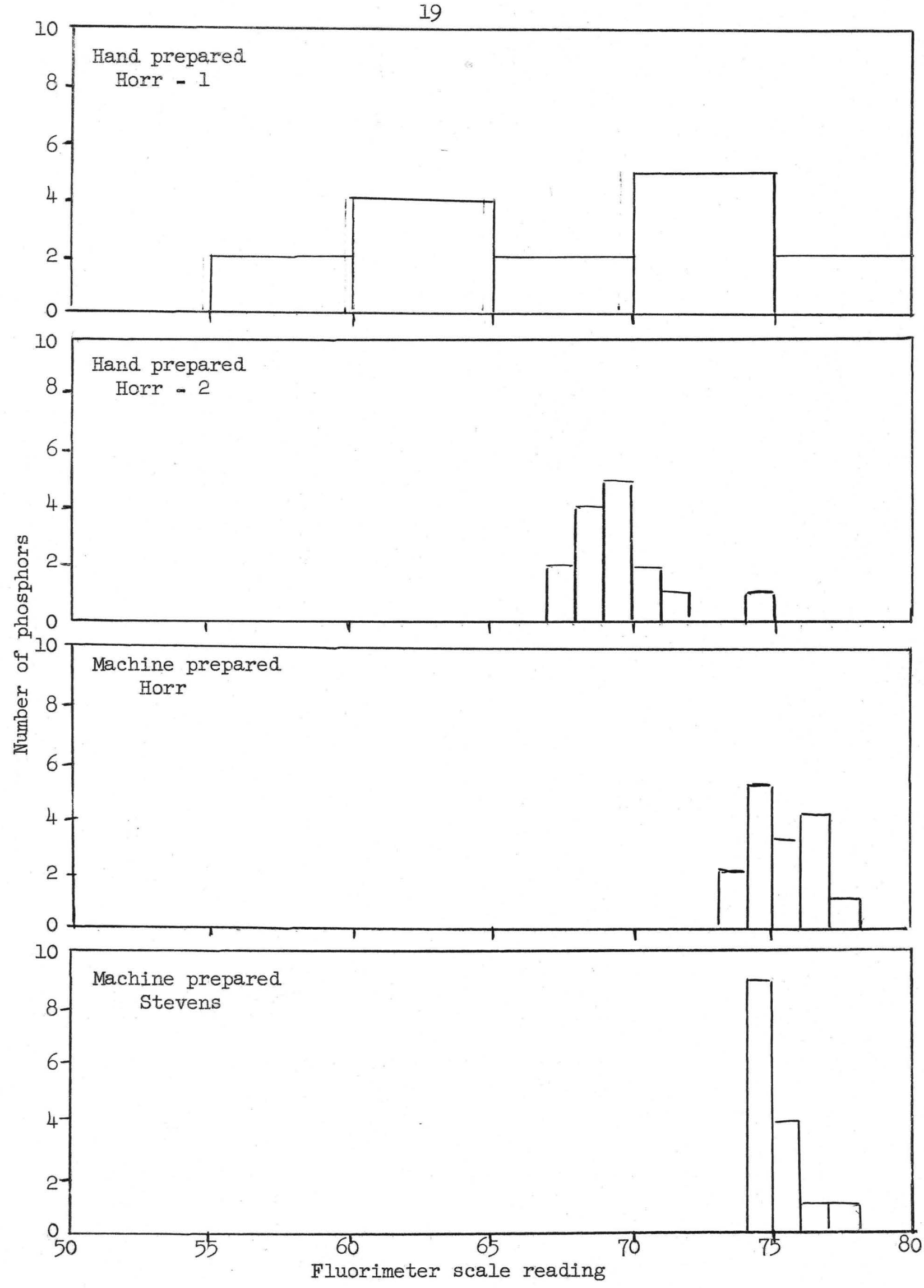

Figure 5.--Histograms showing precision of hand-fused and machine-fused. phosphors. 
rations in a day. The machine on the other hand requires little if any skill to operate and can be run continuously as an easy routine task.

Theoretically, a tireless operator who works unceasingly and makes no mistakes can prepare 160 phosphors by hand per eight-hour day, assuming a total of three minutes for the heating and cooling operations. With the machine, by contrast, 540 phosphors can be prepared in an eight-hour day, starting with weighed flux in the dishes, assuming one minute for inserting and removing dishes from the machine, a five-minute heating period, and a ten-minute cooling period before measurement, or a total of sixteen minutes for preparing each series of eighteen phosphors in the machine. Results with the machine-prepared phosphors are generally free from gross errors that are due to the preparation alone, and the need for repeating the preparation to be sure of a result is reduced.

\section{ADAPTATION OF THE MACHINE TO OTHER LOCALITIES}

The machine may need to be modified in adapting it to other localities because the gas pressure in the lines may be too low to give sufficient heat to melt the flux. In using the machine in Washington, D. C., two gas inlets to the ring burner has to be provided to obtain enough heat. Otherwise, performance of the machine in both localities has been satisfactory. Where the pressure in the gas line is too low gas from a tank may be used.

\section{ADAPTATION TO DISHES OF DIFFERENT DEPTH}

With the dish shown in figure $I$ and with $2 \mathrm{~g}$ of flux the molten flux reaches nearly to the edge of the dish and still covers the center when the machine is in the inclined position. This allows the molten flux to reach 
all surfaces in the dish as the dishes revolve with the machine inclined. This is obviously not so with deeper dishes and changes in design of the machine have to be made to accomplish complete solution of the uranium in the dish into the molten flux. To do this a second lever is provided to give a steeper angle of inclination to the machine so that the molten flux can reach nearly to the edge of the deeper dishes. A suggested routine with a machine modified for deeper dishes, following the preliminary melting of the flux, would be to heat for one minute in the lower inclined position with the molten flux reaching the center of the dish, heat for one minute in the higher inclined position with the flux reaching nearly to the edge of the dish, heat another minute in the lower inclined position, raise the flame to full heat, put the machine in the horizontal position, turn off the gas, and cool.

\section{ACKNOWLEDGMENTS}

The authorswish to acknowledge gratefully the help of a number of colleagues of the Geological Survey: Charles G. Bay and Leonard B. Riley for suggestions in the building of the phosphor-making machine; A. G. King, Wayne Mountjoy, Irving Frost, and John C. Antweiler for confirmatory experiments establishing the usefulness of the machine.

This work is a part of the investigations being undertaken by the Geological Survey on behalf of the Division of Raw Materials of the U. S. Atomic Energy Commission. 


\section{REFERENCES}

(1) Grimaldi, F.S., May, Irving, and Fletcher, M. H. U. S. Geological Survey fluorimetric methods of uranium analysis: U. S. Geol. Survey Circ。199 (1952).

(2) Hernegger, F。, and Karlik, B。, Akad, Wiss. Wien, Math.-naturwiss. KI. Abt。IIa, v。 I44, p. 219 (1935).

(3) Michelson, C. E., The preparation of fluoride melts for use in the fluorimetric method of uranium analysis, HW-36831, U. S. Atomic Energy Comm. (1955)。

(4) Nichols, E., and Slattery, M. K., Opt. Soc. America Jour., v. I2, p. 449 (1926).

(5) Papish, J., and Hoag, L. E., Nat. Acad. Sci. Proc., v. 13, p. 726 (1927)

(6) Price, G. R. Ferretti, R. J., and Schwartz, Samuel, Anal. Chemistry, v. 25, p. 322 (1953).

(7) For a recent review, see Rodden, C. J. Anal. Chemistry, v. 25, p. 1598 (1953).

(8) Sadowski, G. S., with Gentry, J.R。, and Hemphill, H. L., The fluorimetric determination of uranium, pt. I, Mechanical equipment, CNL-23, Clinton National Laboratory

(9) Zimmerman, J. B., Canada Dept. Mines Tech, Surveys, Mines Branch, Memo. Series, v. 114, June 1951.

(10) Zimmerman, J.B., Rabbitts, F. T., and Kornelsen, E. D., Canada Dept. Mines Tech. Surveys, Mines Branch, Radioactivity Div., Topical Rept.TR-112/53 (1953). 